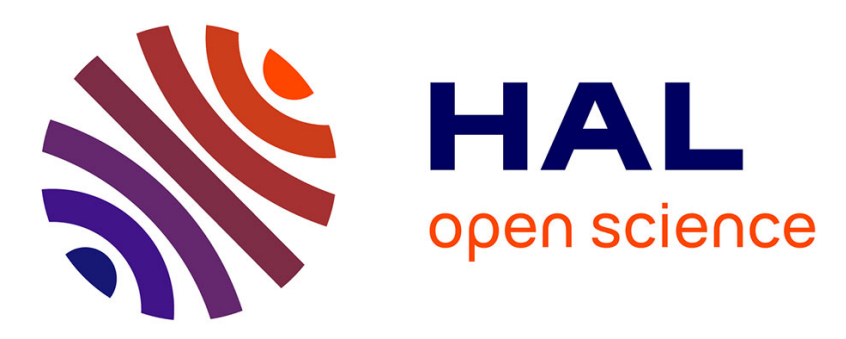

\title{
High-Q Optical Resonators for Laser Stabilization in Microwave Photonics Oscillators
}

Pierre-Henri Merrer, Aude Bouchier, Houda Brahimi, Olivier Llopis, Gilles Cibiel

\section{- To cite this version:}

Pierre-Henri Merrer, Aude Bouchier, Houda Brahimi, Olivier Llopis, Gilles Cibiel. High-Q Optical Resonators for Laser Stabilization in Microwave Photonics Oscillators. Conference on Lasers and Electro-Optics (CLEO Europe), Jun 2009, Munich, Germany. 1p. hal-00379744v2

HAL Id: hal-00379744

https://hal.science/hal-00379744v2

Submitted on 13 Jun 2009

HAL is a multi-disciplinary open access archive for the deposit and dissemination of scientific research documents, whether they are published or not. The documents may come from teaching and research institutions in France or abroad, or from public or private research centers.
L'archive ouverte pluridisciplinaire HAL, est destinée au dépôt et à la diffusion de documents scientifiques de niveau recherche, publiés ou non, émanant des établissements d'enseignement et de recherche français ou étrangers, des laboratoires publics ou privés. 


\title{
High-Q Optical Resonators for Laser Stabilization in Microwave Photonics Oscillators
}

\author{
Pierre-Henri Merrer ${ }^{1}$, Aude Bouchier ${ }^{1}$, Houda Brahimi ${ }^{1}$, Olivier Llopis ${ }^{1}$, Gilles Cibiel ${ }^{2}$ \\ 1. LAAS-CNRS ; Toulouse University ; 7 avenue du Colonel Roche, F-31077 Toulouse, France \\ 2. CNES, 18 avenue Edouard Belin, F-31410 Toulouse, France
}

New resonators are investigated in order to design compact and high performances microwave oscillators. Because of long wavelengths in microwave range, dimensions of resonators are intrinsically large. Secondly, the quality factor of these resonators is now limited to about $2.10^{5}$ at $10 \mathrm{GHz}$ with whispering gallery modes (WGM) sapphire resonators. Nevertheless, it is possible to solve these difficulties if we use optical waves as a carrier for the RF frequencies, for example a $1.5 \mu \mathrm{m}$-laser. Resonators become optical ones, with low dimensions due to short wavelengths. The optical resonator creates an optical frequency comb with microwave spacing. Each mode of this comb is characterized by an optical $\mathrm{Q}$ factor $\left(\mathrm{Q}_{\mathrm{opt}}\right)$ and an equivalent $\mathrm{RF} \mathrm{Q}$ factor $\left(\mathrm{Q}_{\mathrm{RF}}\right)$. $\mathrm{Q}_{\mathrm{RF}}$ is the product of $\mathrm{Q}_{\text {opt }}$ and the RF to optical frequencies ratio. At $1.55 \mu \mathrm{m}$, this frequency ratio is about $10^{4}$ at $20 \mathrm{GHz}$ and $\mathrm{Q}_{\text {opt }}$ must be at least equal to $10^{8}$ to obtain a quality at $20 \mathrm{GHz}$ better than the microwave resonators. We present different high-Q optical resonators and an application of one of them to microwave photonics oscillators.

Like for microwave resonators, WGM can be used in small bulk spheres or disks in silica or quartz, for example. With a scan method [1], using a $1.55-\mu \mathrm{m}$ single-frequency tunable fibered laser to explore the frequency comb of the resonator, we have measured an optical Q factor of about $4.10^{9}$ for a $3.3-\mathrm{mm}$-diameter quartz disk (Fig. 1(a)). The laser is launched in the resonator thanks to a tapered fibre. In spite of the really interesting $Q_{\text {opt }}$ factor of these resonators, their optical transverse multimode behavior and the laser launching difficulties lead us to study another kind of resonators.

These resonators are resonant fibre loops, built with few-meter-long single-mode fibres and fibered couplers [2]. The laser is now directly launched in the resonator with low losses. Thermal effects due to power launching and external perturbations lead to frequency comb instabilities, because of the high $\mathrm{Q}$ factor of the cavity. The laser lock on a resonance loop is necessary, and a Pound-Drever-Hall feedback loop has been used. When the laser is locked, the RF modulation is applied with a Mach-Zehnder modulator (MZM). The optical Q factor is then measured with a vector network analyzer (Fig. 1(b)). We thus demonstrate a Qopt of $3.10^{9}$ in a $20 \mathrm{~m}$-long loop, leading to a $\mathrm{Q}_{\mathrm{RF}}$ of $3.10^{5}$ at $20 \mathrm{GHz}$, better than for a WGM quartz resonator at this frequency.

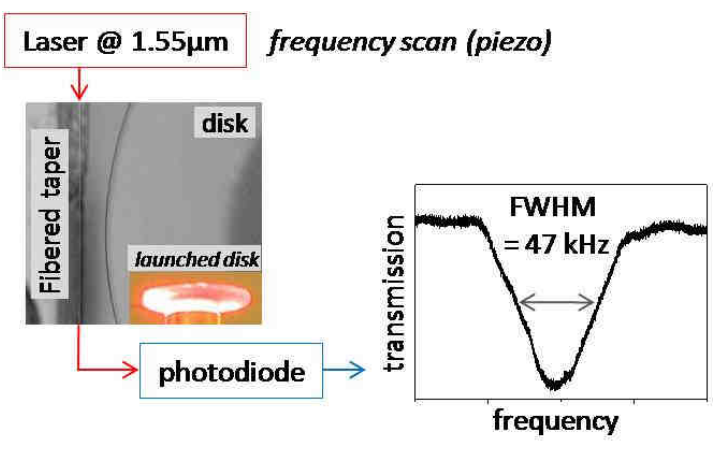

(a) WGM resonator

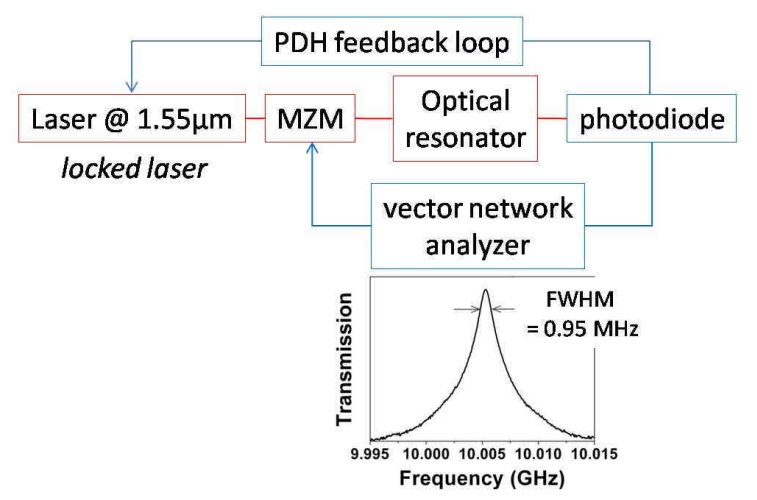

(b) Resonant fiber loop

Fig. 1 Optical Q factor measurement methods used with the WGM resonators (a) or the resonant fibre loop (b).

Despite this high Q factor, the optoelectronic oscillator (OEO) based on this resonator presents a high level of phase noise. We have developed another resonant loop (patent pending) to solve this problem, and obtained a phase noise level of $-90.5 \mathrm{dBc} / \mathrm{Hz}$ at $10 \mathrm{kHz}$ offset from a $10 \mathrm{GHz}$ carrier for this new OEO. A lower $\mathrm{Q}_{\mathrm{RF}}$ factor of $1.2 \times 10^{4}\left(\mathrm{Q}_{\mathrm{opt}} \sim 2.10^{8}\right)$ is extracted from the frequency noise to phase noise transition. We are improving these results thanks to the design of a new resonator and the implementation of a noise model of the whole system.

These optical resonators have really high Q factors. WGM resonators are potentially performing for highly compact devices and fibered resonators are efficient and easily integrated in a complete system. They are really interesting for laser stabilization in photonics microwave applications, as shown with the performances of this $\mathrm{OEO}$, and we are actually improving the efficiency of such optical resonators and oscillators.

\section{References}

[1] P.H.Merrer, O.Llopis, S.Bonnefont, P.Feron and G.Cibiel, "Microwave filtering using high Q optical resonators", Proc. of the European Microwave Conf., Amsterdam 2008

[2] P.H.Merrer, O.Llopis and G.Cibiel, "Laser stabilization on a fiber ring resonator and application to RF filtering", IEEE Photon. Tech. Lett. 20. p. 1399-1401 (2008). 